University of Rhode Island

DigitalCommons@URI

Open Access Master's Theses

1987

\title{
An Examination of the Roles of Sensory Preconditioning and Higher Order Conditioning in Taste Aversion Learning in Rats
}

Paige Dibiasio

University of Rhode Island

Follow this and additional works at: https://digitalcommons.uri.edu/theses

\section{Recommended Citation}

Dibiasio, Paige, "An Examination of the Roles of Sensory Preconditioning and Higher Order Conditioning in Taste Aversion Learning in Rats" (1987). Open Access Master's Theses. Paper 1755.

https://digitalcommons.uri.edu/theses/1755

This Thesis is brought to you for free and open access by DigitalCommons@URI. It has been accepted for inclusion in Open Access Master's Theses by an authorized administrator of DigitalCommons@URI. For more information, please contact digitalcommons-group@uri.edu. 
AN EXAMINATION OF THE ROLES OF

SENSORY PRECONDITIONING AND HIGHER ORDER CONDITIONING

IN TASTE AVERSION LEARNING IN RATS

BY

PAIGE DIBIASIO

A THESIS SUBMITTED IN PARTIAL FULFILLMENT OF THE REQUIREMEMTS FOR THE DEGREE OF

MASTER OF ARTS

IN

PSYCHOLOGY

University of Rhode Island

1987 


\section{ABSTRACT}

This study investigated whether or not the exteroceptive cue of a tone could be conditioned to a taste aversion using the procedures of sensory preconditioning and higher order conditioning. Four conditions - each having a pre (sensory preconditioned) and a post (higher order conditioned) - phase were employed (a total of eight groups with eight subjects per group).

Experimental groups received pairings of a tone with the taste of saccharin either prior to (pre groups) or after (post groups) a conditioning phase in which a LiCl injection was paired with saccharin therefore making the subject ill. The Control 1 (Cl) groups received pairings of no tone and saccharin either before or after the conditioning phase of saccharin and LiCl. Control 2 (C2) groups received the tone and saccharin pairings either prior to or after the conditioning phase, but conditioning for this group paired a saline ( $\mathrm{NaCl}$ ) injection with the taste of saccharin. Control 3 (C3) groups had pairings of no tone with saccharin either before or after the pairing of NaCl with saccharin in the conditioning phase. In the Test I phase, suppression of bar pressing to the tone was measured as an index of a conditioned emotional response. The Test II phase was a two bottle cholce test with water and saccharin. It was hypothesized that exteroceptive cues could become higher order conditioned stimuli and/or 
sensory preconditioned stimuli for internal events, and could influence performance. More specifically it was predicted that the experimental groups would evidence suppression of bar pressing when exposed to the exteroceptive higher order conditioned or sensory preconditioned stimulus (the tone). Suppression of bar pressing was not expected in any other group. In the second phase of testing (Test II) the groups made 1 II to the taste of saccharin during conditioning (Pre-E, Post-E, Pre-Cl, and Post-Cl) were expected to consume significantly less saccharin than the remaining groups. Results did not demonstrate the establishment of a higher order or sensory preconditioned conditioned emotional response, although an aversion to saccharin was evidenced in groups which were made ill to its taste. Results are discussed in terms of "prepared" learning (Seligman, 1970) or a more general set of laws for all kinds of learning. 
ABSTRACT

TABLE OF CONTENTS

LIST OF TABLES

LIST OF FIGURES

vi

LIST OF APPENDICES

vii

1. INTRODUCTION

1

2. METHOD

12

SUBJECTS

12

APPARATUS

12

PROCEDURE

14

3. RESULTS

19

4. DISCUSSION

24

REFERENCES

39 


\section{IIST OF TABLES}

1. Means and SDs of Transformed Response Suppression Ratios During Test I.

2. ANOVA Summary for Transformed Response 23 Suppression Ratios During Test I.

3. Means and SDs of Transformed Saccharin 25 Comsumption Ratios During Test II.

4. ANOVA Summary for Transformed Saccharin Consumption Ratios During Test II. 
LIST OF FIGURES

1. Design across days 16

2. Average saccharin consumption ratios for 27 Test II. 


\section{LIST OF APPENDICES}

Al. Means and SDs of Response Suppression Ratios During Test I

A2. Means and SDs of Saccharin Consumption Ratios During Test II

A3. Mean Number of Responses for Test I During the 38 30 s Prior to the Tone (PT) and 30 s Tone Periods (T) 
An Examination of the Roles Sensory Preconditioning and Higher Order Conditioning Taste Aversion Learning in Rats

The behavior of an organism is influenced by two major forces, its biological makeup and its environment. Given the inflexibility of the biological makeup of an individual organism, the only means of it adapting is through interaction with its environment, i.e., learning. Psychology recognizes two basic learning processes; they are classical conditioning, and operant conditioning. Classical conditioning is the learning of associations between stimuli. It enables an organism to identify and predict important stimuli in its environment. Operant conditioning is the learning of consequences to responses in the presence of specific stimuli. In essence it enables the organism to "do something about" the important stimuli in its environment. Therefore, the environment in (or conditions under) which learning takes place is of significant interest.

Sensory preconditioning and higher order conditioning are phenomena of classical conditioning in which learning takes place under relatively unusual circumstances. That is, the associations between stimuli are further removed hierarchically from first 
order pairings of neutral stimuli with natural elicitors of behavior.

The present study investigated whether or not exteroceptive cues for taste aversion could be conditioned using the procedures of sensory preconditioning and higher order conditioning. Since a taste aversion model provides a response which is considered specific to internal stimuli (usually illness). Exteroceptive stimuli in the environment are not as easily conditioned on a first order basis (Morrison \& Collyer, 1974; Seligman, 1970). It was of theoretical importance to determine if exteroceptive stimuli for taste aversions could be acquired by more removed pairings. Research directly examining the roles of both sensory preconditioning and higher order conditioning using exteroceptive stimuli as the higher order and sensory preconditioned stimuli in a taste aversion paradigm has not been conducted. The present research was undertaken to study this speciftc paradigm. Avoldance responding and the conditioned emotional response (CER) have been the topics of an immense body of psychological research. Avoidance behaviors are instrumental responses that postpone and avoid exposure to aversive stimulation. The learning involved is most often conceptualized as classical conditioning. In the classical conditioning paradigm, the experimenter 
presents a neutral stimulus just before the onset of an unconditioned aversive stimulus (UCS) which elicits an unconditioned response (UCR). Through the repeated presentation of the neutral stimulus followed by the UCS, the neutral stimulus is associated with the UCS and becomes a conditioned stimulus (CS). After the repeated pairings, the presentation of the CS alone will elicit a conditioned response (CR). This CR is usually similar to the UCR. When avoidance behaviors are learned, the subject makes an instrumental avoidance response after the CS onset but prior to the UCS onset thereby avoiding the UCS onset and controlling its presentation (Brodgen, Lipman, \& Culler, 1938).

The conditioned emotional response (CER) is an indirect measure of the emotional basis of avoidance behavior. It provides information about the effect of a conditioned stimulus on an animal's ongoing (free operant) behavior. It implies that the emotional response to the classically conditioned stimulus affects on-going operants. Estes and Skinner (1941) devised this procedure as a measure of an emotional "state". They classically paired a tone with a footshock so that the tone would become an aversive CS. This aversive CS was then introduced into an independent (free operant) situation where the rat was bar pressing for food. The effect of the tone on the rate of bar pressing was 
measured. The disruption of a "hunger-motivated behavior" upon the presentation of a CS or the conditioned suppression of the response to a CS provided an indirect index of the animal's "emotional state". Research in the area of avoidance behaviors has included topics such as the method and timing by which CS and UCS are paired (Bitterman, 1964, 1965; Boneau, 1958; Ebel \& Prokasy, 1963; Heth \& Rescorla, 1973; Kamin, 1965; Prokasy, Hall, \& Fawcett, 1962), how long the avoidance response persists (Boyd \& Levis, 1976; Hawk \& Riccio, 1977; Neill, 1980; Spring, 1972), and under what conditions it is extinguished (Corriveau \& Smith, 1978; Monti \& Smith, 1976; Page, 1955; Page \& Hall, 1953; Schiff, Smith, \& Prochaska, 1972; Shipley, Mock, \& Levis, 1971).

A plethora of information is also available regarding the conditioning of first order stimuli, that is, the repeated direct pairing of the UCS with a neutral stimulus which in turn becomes a first order CS (Pavlov, 1927). For example, a tone (CS) paired with a footshock (JCS), which evokes a "jump-up" response (UCR), comes to elicit a jump-up response (CR) when presented without the UCS.

Stimuli other than the first order CS in the environment can influence learning as well. The influence of stimuli other than those which have become 
first order CSs and which are associated with the first order CSs needs to be examined. Their conditioned properties in the establishment and maintenance of avoidance responding and CERs are of significant interest.

Two processes by which stimuli beyond the first order CS are established as conditioned stimuli are higher order conditioning and sensory preconditioning. The basic paradigm for sensory preconditioning (SPC) involves the repeated pairing of two neutral stimuli (S2-SI) and then classically conditioning a response to one of them (SI). After a conditioned response has been established to Sl, the other neutral stimulus (S2), previously paired with Sl (sensory preconditioned), is presented and the response to S2 is measured. If SPC has occurred, a CR, similar to the one elicited to SI, is elicited when $\mathrm{S} 2$ is presented in the absence of both the UCS and Sl, the first order CS (Brodgen, 1939).

Higher order conditioning occurs when two stimuli (CS2-CSI) are given pairing trials after CSI has been repeatedly paired with the UCS. CS2, which has never been paired with the UCS is then presented alone. Higher order conditioning is demonstrated when CS2 presented alone elicits a similar conditioned response (CR) to the CR to CSI.

The present research was designed to demonstrate 
sensory preconditioning and higher order conditioning within a conditioned taste aversion paradigm. Taste aversions, for the most part, are affected by the same factors of learning as other behaviors with the exceptions that (1) they can be learned over long delays (extended CS-UCS intervals), (2) they are learned very quickly, often in one trial,(3) they are retained over extended periods of time, and (4) some stimuli are more easily conditioned in this paradigm than others (Bond 8 DiGuisto, 1976; Colby \& Smith, 1977; Dragoin, 1971; Dragoin, Hughes, Devine, \& Bentley, 1973; Kalat, 1974; Revusky, \& Garcia, 1970; Smith \& Roll, 1967). The conditioning of a taste aversion follows a classical conditioning paradigm. A taste (CS) is paired with a toxin (UCS) which in turn produces illness (UCR) and subsequently causes a conditioned aversion to the taste (Garcia, Kimeldorf \& Koelling, 1955).

A variable which is important to taste aversion conditioning is stimulus relevance. Stimulus relevance refers to the differential associability of specific kinds of stimuli with specific kinds of responses. It has been shown that connections between gustatory stimuli are more readily associated with internal events such as gastrointestinal illness than with external events such as footshock and external cues such as visual or auditory stimuli are more readily associated 
with external events such as shock than with internal events. Early taste aversion research indicated no association between external stimuli and internal events (Garcia B Boelling, 1966). Garcia and Boelling using sweet "bright, noisy" water showed significant avoidance of tasty water (saccharin) when the taste was paired with irradiation (the UCS). However, avoidance of tasty water was not demonstrated after conditioning trials which paired it with the shock UCS. Nor was there avoidance of bright-noisy water when it had been paired with irradiation as the UCS. The authors proposed that this "stimulus relevance" (i.e., the conditionability of taste and illness) has to do with natural selection. They suggest that learning that gustatory and olfactory cues can signal gastrointestinal distress has survival value. Therefore aminals that easily associate smells or tastes of foods that make them sick are more likely to survive (Seligman, 1970; Seligman \& Hager, 1972).

Garcia and Boelling (1966) in addition to other researchers (Braveman \& Capretta, 1965; Dietz \& Capretta,1966; Garcia, McGowan, Brvin, \& Boelling, 1968; Larsen $\&$ Hyde, 1977) have indicated that conditioned taste aversions were very specific aversions and would only be conditioned to gustatory cues which were unfamiliar and introceptive (See Revusky \& Garcia, 1970 for a complete review). More recent studies suggest 
that although there is a "preparedness" (i.e., a biological predisposition) (Seligman, 1970; Seligman, 1972; Seligman \& Hager, 1972) for the association of taste cues and gastrointestinal distress, exteroceptive cues can become conditioned stimuli for taste aversions. Bxternal cues such as tones and lights, however, are not conditioned as readily to internal states, as are tastes and smells (Archer, Sjoden, \& Carter, 1979; Berk, \& Miller, 1978; Best, Best, \&̊ Mickley, 1973; Krane, 1980; Morrison, \& Collyer, 1974).

With respect to the conditionability of exteroceptive stimuli, Best et al. (1973) found that after a black compartment had been paired with illness, rats avoided it in a choice test and, in a subsequent experiment, showed suppressed responding in it. In a more recent study, Krane (1980) showed that novel exteroceptive cues could be conditioned stimuli to an illness response and that a flavor-illness association could even be blocked by exteroceptive cues. Similarly, Morrison and Collyer (1974) examined the "mediating" value of a taste cue in the development of an aversion to exteroceptive cues. Their results indicated conditioning of the exteroceptive cues to the illness did occur if a "mediating" taste cue was present. However, conditioning of the CR to the exteroceptive cue did not occur if the pairing of the exteroceptive cue (a 
light) and the taste cue occurred prior to the taste-illness pairing. Thus sensory preconditioning was not demonstrated.

Other studies have also examined taste aversions, higher order conditioning and/or sensory preconditioning. Rescorla (1980) found evidence of sensory preconditioning in a taste aversion paradigm. He employed taste cues only with a toxin and audio-visual cues with shock - never exteroceptive cues with illness. Employing a taste aversion paradigm, Archer and Sjoden (1982) used an exteroceptive stimulus (context) as the CSI to be paired with illness in both the higher order conditioning and sensory preconditioning groups. A taste was used as the CS2, thus allowing the exteroceptive cue to serve as the mediator for the taste-illness association. The results demonstrated that exteroceptive cues facilitated the development of higher order and sensory preconditioned taste-illness associations.

The present study was designed to examine the establishment of higher order conditioning and sensory preconditioning of a taste aversion to an exteroceptive CS2 using a taste cue as the first order CS.

Subjects were exposed to conditions which paired a tone with the taste of saccharin. In sensory preconditioning groups (denoted as the "Pre" groups), 
this pairing occurred prior to the CS-UCS pairing. In higher order conditioning groups ("Post" groups) the tone-taste pairing occurred after the CS-UCS pairing. This was the order variable.

The design employed began with a bar press training phase to establish a "hunger-motivated" response with a constant rate (Estes \& Skinner, 1941). Training was followed by the cue exposure then conditioning phases for the "Pre" groups or the conditioning then cue exposure phases for the "Post" groups. Cue exposure consisted of the pairing of two stimuli (the taste of saccharin and a tone) while the conditioning phase was the classical conditioning of the aversion through the taste-illness pairings. Two testing phases followed. Test I provided an examination of the conditioned emotional response through the suppression of bar pressing to CS2 (the tone) and Test II measured the first order avoidance response to the taste of saccharin.

In order to provide appropriate controls, eight groups were needed. Experimental groups (Pre-E and Post-E) had both tone-taste pairings in the cue exposure phase and taste-illness pairings in the conditioning phase. To control for possible changes in responding due to tone exposure alone, control groups Pre-Cl and Post-Cl were needed. Subjects in these groups were 
exposed to the pairing of "no tone" (the tone was not presented) and saccharin during cue exposure and taste-illness pairings in the conditioning phase. Illness exposure control groups were included also. Subjects in the no illness control groups (Pre-C2, Post-C2, Pre-C3, \& Post-C3) were given saline injections in the conditioning phase to provide comparison groups which should not show a taste-illness association without the toxin. Groups Pre C2 and Post C2 were exposed to tone-taste pairings during cue exposure and taste-no illness pairings during conditioning. This was to control for sensitization due to toxin exposure per se. Control groups Pre-C3 and Post-C3 were not exposed to the tone and were not made ill. These groups received the pairing of no tone with the taste of saccharin in the cue exposure phase and the pairing of the taste of saccharin with no illness during conditioning. Collectively, the control groups provided stimulus arrangements which allowed the isolation, manipulation, and examination of each component of the procedure in order to account for changes in responding attributable to conditioning, exposure to the respective taste and tone stimuli alone and the toxin alone.

It was hypothesized that exteroceptive cues could become higher order conditioned stimuli or sensory preconditioned stimuli for internal events, and 
subsequently influence performance. More specifically, it was predicted that groups Pre-E and Post-E would evidence suppression of bar pressing (a CER) when exposed to the higher order conditioned or sensory preconditioned stimulus (the tone) during the Test I phase. Suppression of bar pressing was not expected in any other group. In the second phase of testing (Test II), the avoidance (taste preference) test, it was predicted that the groups made ill to the taste of saccharin (Pre-E, Post-E, Pre-Cl, and Post-C1) would consume significantly less saccharin than groups which did become ill to the taste of saccharin (Pre-C2, Post-C2, Pre-C3, and Post-C3.

Method

Subjects

Subjects were 64 naive male Sprague-Dawley rats from the Charles River Breeding Laboratory. Each rat weighed between 250 and 350 \& at the start of the experiment prior to food or water deprivation. They were maintained at approximately $80 \%$ of their free feeding weight throughout the remainder of the study. All rats were randomly assigned to one of the eight groups.

\section{Apparatus}

The experimental chamber was a $64 \times 64 \times 60 \mathrm{~cm}$ 
plywood box which had been sound deadened with ceiling tiles. It had a 15 watt house light mounted at the top of the back wall and a ventilation fan and vents. The chamber opened from the front and housed the lever box and lick box, along with the appropriate equipment during the different phases of the experiment. A $25.5 \mathrm{x}$ $27 \mathrm{~cm}$ enclosure having an $8 \mathrm{ohm}$ speaker was present in the chamber at all times. The apparatus was wired using standard electromechanical programming equipment.

During the Training and Test I phases a $23.5 \times 22 \times$ $20 \mathrm{~cm}$ lever box with a metal rod floor was used. A lever ( $5 \mathrm{~cm}$ from the floor and centered) and food cup to the right of the lever were mounted on one wall. A Gerbrands feeder was employed to deliver Noyes $45 \mathrm{mg}$ food pellets on the appropriate schedule.

The Cue Exposure phase took place in the same experimental chamber with the lever box replaced by a $23.5 \times 22 \times 20 \mathrm{~cm}$ lick box. This box had two Plexiglas and two metal walls. In the center of one of the metal walls, $4 \mathrm{~cm}$ from the floor, was a $6.5 \mathrm{~cm}$ rubber stopper with $3.5 \mathrm{~cm}$ of $.5 \mathrm{~mm}$ metal tubing through it. This tubing was attached to a rubber hose which was connected to a Multifit glass syringe mounted on a DSI liquid pump which delivered fluids.

A speaker, placed in the rear of the experimental chamber was employed along with an EICO sine wave tone 
generator to produce the CS tone. This tone generator produced a $2500 \mathrm{~Hz}$ tone with an amplitude of $77 \mathrm{~dB}$.

The Conditioning and Test II phases took place in the colony in cages other than the rats' home cages. Standard galvanized front opening cages with water bottles were used.

A.1\% (weight to volume) saccharin solution was used as the taste CS. The lithium chloride (LiCl) solution was $3.6 \mathrm{MEq}$ (Infurna, Steinert, Freda, \& Spear, 1979) and was administered via an intraperitoneal (ip) injection of $1 \mathrm{ml} / \mathrm{kg}$ bodyweight. The sodium chloride (NaCl) solution was a . $15 \mathrm{MEq}$ solution and a dosage of 1 $\mathrm{ml} / \mathrm{kg}$ bodyweight was given. Plastic syringes and $23 \mathrm{~g} \mathrm{x}$ $3 / 4$ gauge needles were used to administer the LiCl or NaCl solution.

\section{Procedure}

Eight groups were employed in order to include the experimental and all appropriate controls. All groups were handled, trained and tested under the same conditions. Figure 1 shows the design of the study.

Handling. All subjects were handled twice for five consecuative minutes, once prior to the start of the experiment and then again after the start of food deprivation but before bar press training. 
Figure 1. Design across days. 


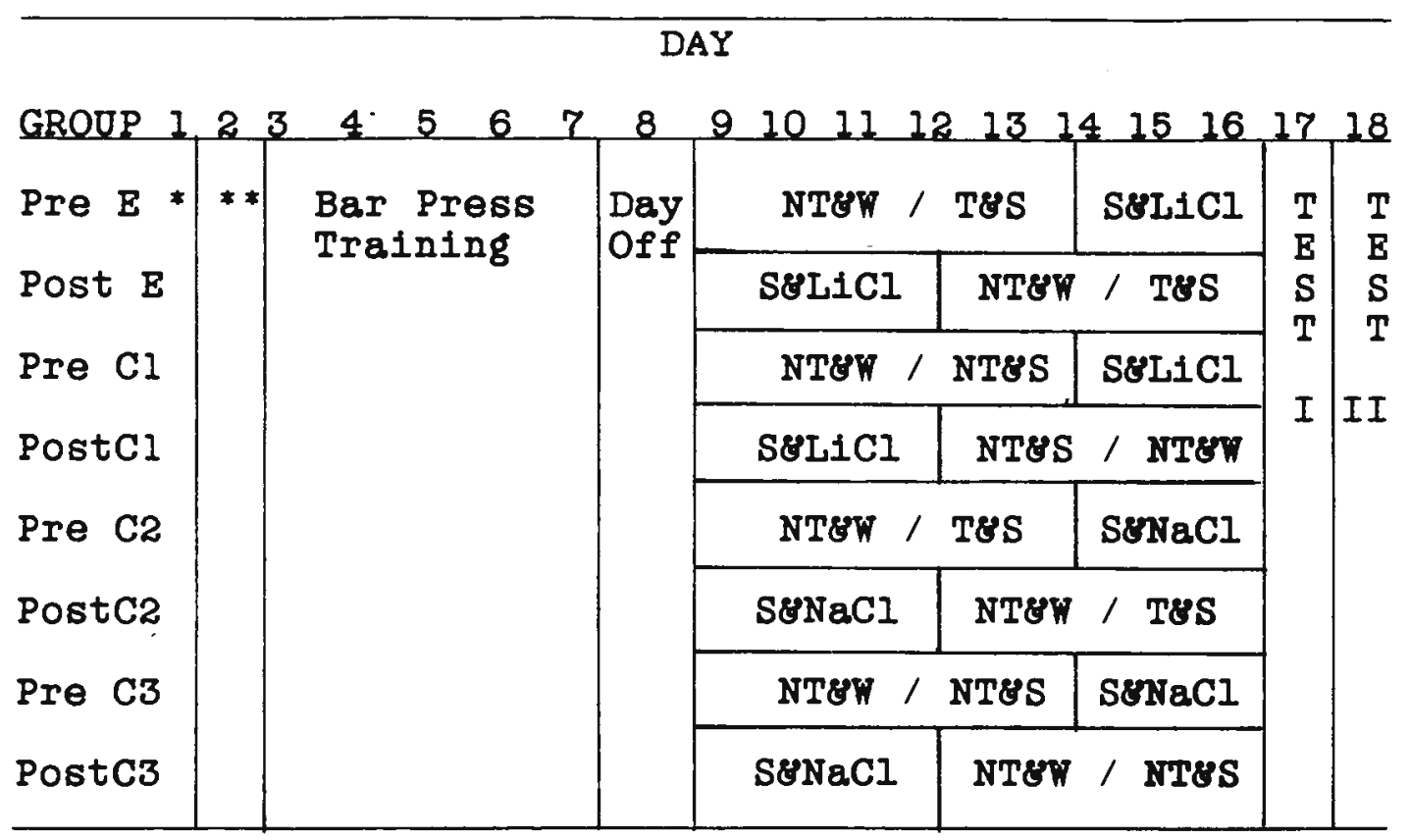

* = acclimation

** = shaping

$S=$ saccharin

$W=$ water

$T=$ tone

$\mathrm{NT}=$ no tone

LiCl=lithium chloride ( $1 \mathrm{ml} / \mathrm{kg}$ )

$\mathrm{NaCl}=$ sodium chloride ( $\mathrm{ml} / \mathrm{kg}$ ) 
Training. At the start of the experiment subjects were food deprived for $48 \mathrm{hrs}$. They were then placed in the training apparatus for a $10 \mathrm{~min}$ acclimation period. Five food pellets were available in the food cup and the equipment was in operation. Twenty-four hrs later magazine training and shaping took place. Training sessions began the following day on a VI-2O s schedule. There were five training sessions each 30 min long. Subjects were required to meet a floor criterion of 100 responses per session by the second day of training. On day four of bar training, water deprivation began. All subjects were given $20 \mathrm{~min}$ free access to water 30 min after the completion of the daily training session. The cue exposure phase, for "Pre" groups, or taste aversion phase, for "Post" groups, began 48 hrs after bar training had been completed.

Cue Exposure. Cue exposure took place in five sessions, 24 hrs apart. Each session consisted of ten trials, eight of which were water exposure and two of saccharin exposure. The order of saccharin and water trials was randomly determined from session to session with the constraint that the first trial was always a water trial. This phase consisted of the pairing of a tone with saccharin and the pairing of no tone and water for groups Pre-E, Post-E, Pre-C2, and Post-C2. No tone was paired with saccharin and water for groups Pre-Cl, 
Post-C1, Pre-C3, and Post-C3 (see Figure 1).

On each trial the subject was placed in the lick box with only the fan running. To start a trial the house lights came on, the Plexiglas barrier was raised and the fluid needle was made available. For the first few trials of the first session subjects were prompted to lick by making a drop of water available through the needle during the water trials. The first lick of each trial, depending on the condition being run, turned on the tone for $3 \mathrm{~s}$ and provided a drop of saccharin or presented no tone and the appropriate liquid (water or saccharin). The house light then went off and the Plexiglas barrier was replaced. During this phase, if a response (a lick which turned on the apparatus) had not been made within 5 min for any given trial, that trial was ended and rerun. If no response occurred for any two consecutive trials the session was ended. If two sessions were discontinued due to non-responding, the subject was not given access to water that day in order to increase the deprivation state. If three discontinued sessions occurred, the subject was eliminated from the study and replaced with a new subject. Thereby assuring the contiguity between the tone and saccharin in the experimental groups and the appropriate form of stimulus contiguity in the control groups. 
Conditioning. This phase was conducted on three consecutive days. Subjects were placed in standard front opening cages in the colony room (not home cages) and were given 3 min access to a. .1\% saccharin solution in a free operant situation. They were then returned to their home cages. Approximately 10-15 min later they were given an ip injection of LiCl or $\mathrm{NaCl}$, as indicated by the respective conditions, and returned to their home cages. All subjects were give 20 min free access to water 30 min after injections.

Testing I. All subjects were tested on day 17 following both cue exposure and conditioning phases. Subjects were placed in the lever box apparatus to bar press for food on a VI-20 s schedule. On a VT-6 min schedule (3-9 min), responding was measured for $30 \mathrm{~s}$ followed by the onset of the tone for $30 \mathrm{~s}$ during which responding was also recorded. This session was approximately $35 \mathrm{~min}$ long, with five intervals during which responding was measured.

Testing II. This phase was conducted the day after Testing I (on day 18). All subjects were placed in the same apparatus used during taste aversion and given a two bottle choice test. They were given 20 min free access to water and saccharin in as preference test. The amount (ml) of each fluid consumed was recorded. 


\section{Results}

Testing I. Response frequencies were used to calculate suppression ratios. The suppression ratio employed was of the form $B /(A+B)$ (Church, 1969), where $A$ was the number of responses (bar presses) made in the 30 s prior to the test stimulus and $B$ was the number of responses made during the $30 \mathrm{~s}$ presentation of the test stimulus (the tone, CS2). This ratio is a measure of ongoing behavior and ranges from 0 to 1 . A ratio of 0 to .49 indicates some level of suppression ( 0 being complete suppression of bar pressing during the tone). A value of .5 means there was no suppression and no facilitation (this value was assigned when no responding during both the tone and no tone periods occurred). Values from .51 to 1 are indicative of facilitation. The means and standard deviations of these ratios were calculated for each group for data from trials 1 through 5 and are presented in Appendix Al. The raw data was then transformed using an arcsine transformation for proportions (Levy,1975) to normalize the data prior to conducting an ANOVA.

Hartley's test for homogeneity of variance was performed on the transformed data. Results indicated no violation of homogeneity $(F \max (40,7)=24.52$, n.s.). A comparison of this value was made with the largest value in the distribution of the studentized Range Statistic 
table (Winer, 1962), 1.e., $F \max (10,7)=24$ with an alpha-level of .05. In addition, each cell of the design was treated separately making this a very conservative test. A $4 \times 2 \times 5$ (conditions $\times$ order $x$ trials) repeated measures ANOVA of the transformed suppression ratios was conducted. This analysis examined differences among groups, order, trials, and their interaction. The analysis yielded a significant trials effect, $F(4,224)=3.65, p<.05$, and all other effects were non-significant. The transformed means and standard deviations are presented in Table 1 ; the ANOVA summary table for this analysis is presented in Table 2 . A Newman-Reuls follow-up test was performed to clearly examine the trials effect. Results indicated significant differences between trial 1 and all other trials ( $p<.05)$.

Testing II. The proportion of saccharin consumed in the 20 min test period was calculated. The $B /(A+B)$ ratio was used in this phase as well, A was the amount of water consumed in $\mathrm{ml}$ and $B$ was the amount of saccharin consumed in $\mathrm{ml}$. Means and standard deviations of consumption values were determined for each group and are presented in Appendix A2. Ratios ranging from 0 to .49 indicate low saccharin consumption ( 0 being complete suppression), .5 is an indicator of equal water and saccharin consumption (this value was assigned when 
Table 1

Means and SDs of Transformed Response Suppression Ratios During Test I

\section{TRIALS}

\begin{tabular}{|c|c|c|c|c|c|c|c|}
\hline CONDITION & ORDER & & 1 & 2 & 3 & 4 & 5 \\
\hline & Pre & $\underline{\underline{\mathbf{M}}}$ & 1.3 & 1.93 & 1.6 & 1.61 & 1.73 \\
\hline$E$ & & SD & .92 & .8 & .39 & .34 & .78 \\
\hline & Post & & 1.31 & 1.48 & 1.86 & 1.86 & 1.63 \\
\hline & & & .44 & .32 & .65 & .63 & .34 \\
\hline & Pre & & 1.05 & 1.96 & 1.66 & 1.53 & 1.48 \\
\hline $\mathrm{Cl}$ & & & .85 & .8 & .76 & .69 & 1.04 \\
\hline & Post & & 1.62 & 1.45 & 1.78 & 1.50 & 1.66 \\
\hline & & & .64 & .41 & .46 & .71 & .39 \\
\hline & Pre & & 1.25 & 1.57 & 1.75 & 1.66 & 1.93 \\
\hline $\mathrm{C} 2$ & & & .57 & .4 & .44 & .29 & .54 \\
\hline & Post & & 1.59 & 1.55 & 1.54 & 1.62 & 1.53 \\
\hline & & & .68 & .32 & .27 & .23 & .32 \\
\hline & Pre & & 1.12 & 1.53 & 1.32 & 1.79 & 1.18 \\
\hline C3 & & & .23 & .26 & .21 & .57 & .75 \\
\hline & Post & & 1.42 & 1.35 & 1.44 & 1.76 & 1.91 \\
\hline & & & .43 & .66 & .46 & .32 & .54 \\
\hline
\end{tabular}


Table 2

ANOVA Summary for Transformed Response Suppression Ratios During Test I

\begin{tabular}{lrrrr}
\hline SOURCE & SS & DF & MS & F \\
\hline CONDITION & 1.010 & 3 & .337 & 1.077 \\
ORDER & .158 & 1 & .158 & .505 \\
CXO & .720 & 3 & .240 & .767 \\
ERROR & 17.528 & 56 & .313 & \\
TRIALS & 4.643 & 4 & 1.610 & $3.651^{*}$ \\
CXT & 2.280 & 12 & .190 & .597 \\
OXT & 2.908 & 4 & .727 & 2.286 \\
CXOXT & 4.072 & 12 & .339 & 1.066 \\
ERROR & 71.308 & 224 & .318 & \\
\hline TOTAL & 104.627 & 319 & & \\
\hline
\end{tabular}

$* p<.05$ 
neither water nor saccharin was consumed) and above .5 to 1 means more saccharin was consumed ( 1 indicating only saccharin was consumed). An arcsine transformation (Levy, 1975) was used to normalize the data. Results of an Fmax test indicated no violation of homogeneity $(F \max (8,7)=7.02$, n.s. $)$ and were followed by a $4 \times 2$ (condition $x$ order) ANOVA of the transformed consumption values. These values are presented in Table 3 and Figure 2. A significant condition effect $(F(3,53)=24.59, p<.05$ ) was found (see Table 4 for ANOVA summary table). Newman-Keuls follow-up tests indicated that groups which became ill to saccharin (Pre-E, Post-E, Pre-Cl, and Post-Cl) consumed significantly less saccharin ( $p<.05)$ than the no illness control groups (Pre-C2, Post-C2, Pre-C3, and Post-C3).

Discussion

The results of this study do not support the hypothesis that exteroceptive cues can become sensory preconditioned or higher order conditioned stimuli for taste aversions. No suppression of bar pressing was evidenced during the presentation of the tone for either SPC Or HOC groups in the Test I phase. However, Test II did demonstrate the establishment of a taste aversion for subjects which were made ill to the taste of saccharin. This indicates that although the taste of 
Table 3

Means and SDs of Transformed Saccharin Consumption Ratios During Test II

QRDER

\begin{tabular}{crrr} 
CONDITION & PRE & POST \\
\hline $\mathrm{E}$ & $\mathrm{M}$ & 1.29 & 1.02 \\
& $\mathrm{SD}$ & .33 & .20 \\
$\mathrm{C1}$ & & .03 & .93 \\
& & .53 & .45 \\
$\mathrm{C} 2$ & & .95 & 2.03 \\
& & .34 & .47 \\
& & 1.91 & 1.76 \\
$\mathrm{C3}$ & .30 & .39
\end{tabular}


Figure 2. Average saccharin comsumption ratios for Test II. 


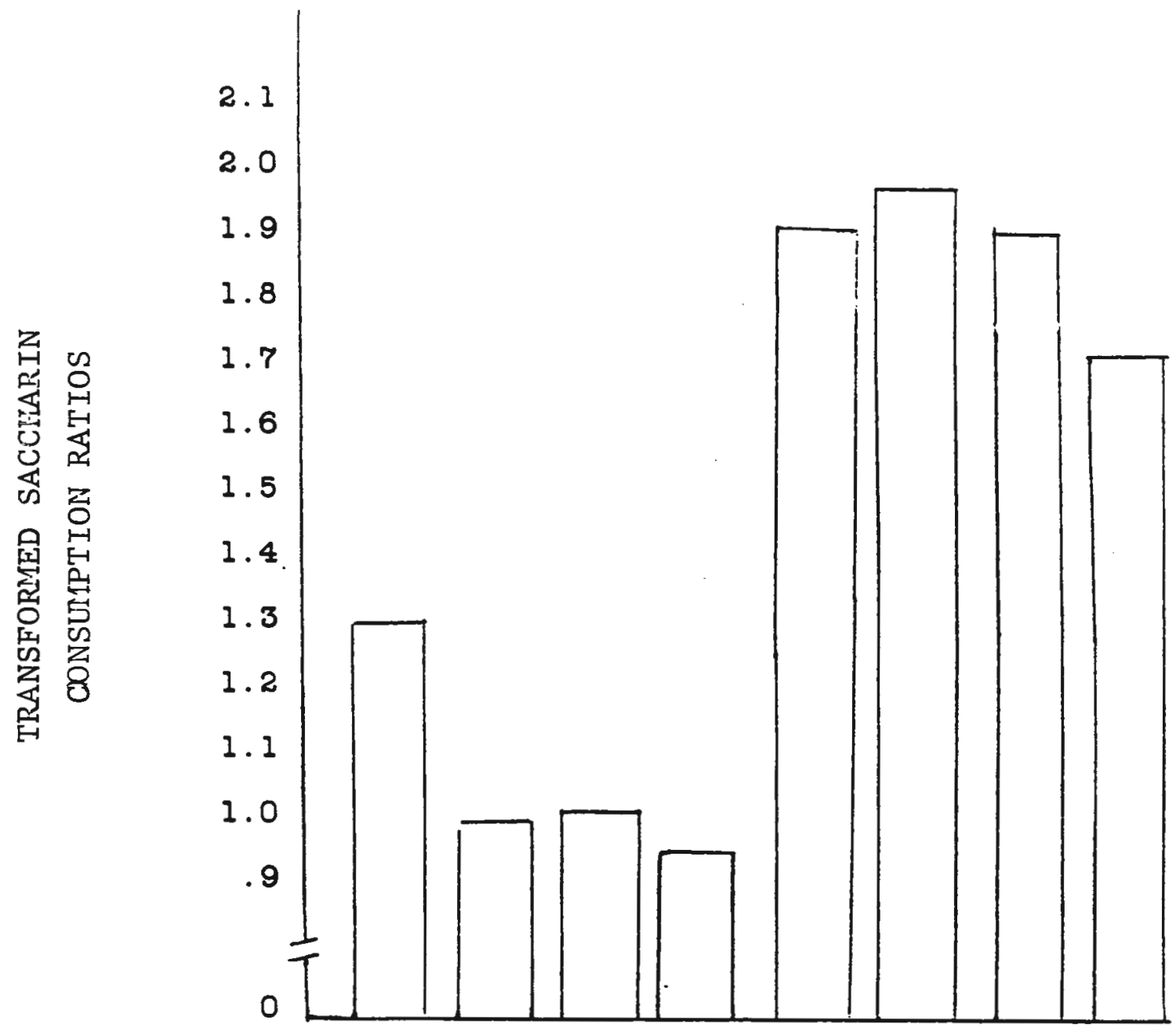

PRE POST PRE POST PRE POST PRE POST $\begin{array}{llllllll}\mathrm{E} & \mathrm{E} & \mathrm{Cl} & \mathrm{Cl} & \mathrm{C2} & \mathrm{C2} & \mathrm{C} 3 & \mathrm{C3}\end{array}$ GROUP 
Table 4

ANOVA Summary for Transformed Saccharin Consumption

Ratios During Test II

\begin{tabular}{|c|c|c|c|c|}
\hline SOURCE & SS & $\mathrm{DF}$ & MS & $F$ \\
\hline CONDITION & 11.218 & 3 & 3.739 & $24.599 *$ \\
\hline ORDER & .180 & 1 & .180 & 1.184 \\
\hline $\mathrm{CzO}$ & .247 & 3 & .082 & .539 \\
\hline ERROR & 8.058 & 53 & .152 & \\
\hline TOTAL & 19.703 & 60 & & \\
\hline
\end{tabular}

* pr. .05 
saccharin was avoided by experimental and Cl groups relative to no illness controls (as evidenced in Test II) no association between the tone and the illness was established in the SPC or HOC paradigms. It is necessary to consider explanations for this discrepancy.

These results are consistent with those of Braveman \& Cappretta (1965), Garcia \& Koelling (1966), Larsen 8 Hyde (1977), and others. The establishment of higher order and sensory preconditioned associations do not occur easily when the conditioned and unconditioned stimuli are exteroceptive and interoceptive. Seligman (1970) views such results as supporting his position of "biological preparedness". This view states that rats are biologically prepared to associate interoceptive stimuli such as tastes with internal events like illness; in addition, there is a "contrapreparedness" to associating exteroceptive stimuli (lights, tones, etc.) with internal events. Contrapreparedness is the tendency for stimuli to remain unassociated after repated pairings. Such a position views learning biologically "prepared" and "contraprepared" responses as being established in a manner different from that of "non-prepared" responses. "Non-prepared" responses are not any more (or less) likely to occur because of a biological predisposition. They are learned in a manner consistant with laws of learning whereas prepared and 
contraprepared responses are facilitated (or restricted) due to biological contraints.

Such a position is consistant with the findings of the present investigation. A taste aversion was learned but neither sensory preconditioning nor higher order conditioning occurred. This may have been due to the cross-modal nature (external - internal) of the CS and UCS or the "contrapreparedness" of the association.

Klosterhalfen and Klosterhalfen (1985) propose a different perspective. After a rather extensive review of the literature, in an attempt to examine if there is a general set of laws for all kinds of learning (taste aversion and traditional), they suggest that many of the differences found between conditioned taste aversion and traditional learning (such as those indicated by the present research) are due to the specific characteristics and properties of the stimuli employed in conditioned taste aversion learning and not actual differences in the kinds of learning. They state that most of the "learning phenomena" which occur in conditioned taste aversion learning also occur in traditional learning, and vice versa. These and other researchers (Archer et al, 1979; Archer \& Sjoden, 1982; Best et al, 1973; Klein, Freda, \& Mikulka, 1985; Krane, 1980; Sullivan, 1984) cite literature which provide support for a general set of laws of associative 
processes. More specifically, such research has provided evidence of external influences on internal responses. In light of these two views, a closer examination of the results of this study is called for. If "prepared" learning has taken place it should occur without regard to test context. If the taste had become an aversive stimulus according to a "preparedness" perspective, the taste should be aversive in all situations because taste is "prepared" to be associated with illness and context is "contraprepared" to be associated with illness (Garcia \& Boelling, 1966). Test II demonstrates a taste aversion was formed to the taste of saccharin. Animals injected with LiCl after drinking saccharin (Pre-E, Post-E, Pre-Cl, and Post-Cl) during the conditioning phase, later consumed significantly less saccharin than no illness controls (Pre-C2, Post-C2, Pre-C3, and Post-C3) in Test II. Animals in the Post-E and Post-Cl groups continued to consume saccharin in the cue exposure phase - which occurred after conditioning and before Test II. Since the taste had become an aversive stimulus, as evidenced in Test II, the taste of saccharin should have been avoided in all contexts after the Conditioning phase including the Cue Bxposure phase - for animals in the Post-E and Post-Cl groups. However, none of the subjects in these groups had to be dropped from the 
study due to a lack of responding during Cue Exposure, indicating that saccharin had become an aversive stimulus in one context (Test II) but not in the other (Cue Exposure). This seems to contradict preparedness. Another phenomena found in conditioned taste aversion learning is the effect of CS preexposure. Typically, CS preexposure effects in a conditioned taste aversion paradigm account for weaker and often non-existant CRs. Although CS preexposure does occur in this experiment (sensory preconditioned groups), the effect of CS preexposure is not evidenced. There were no differences in the degree of the taste aversion evidenced by CS preexposed (SPC) groups and non-preexposed (HOC) groups. Preexposed subjects that were made ill avolded the aversive taste to a similar degree as the non-preexposed subjects made ill and significantly more than the subjects not exposed to the aversive UCS. Once again, CS preexposure (the Cue Exposure phase for SPC groups) took place in a context different from that of the Conditioning and Test II.

As cited above, several recent pieces of research have found that contextual cues play a major role in learning - including taste aversion learning. In the present study the Cue Exposure and Test I phases took place in a completely different context than the Conditioning and Test II phases. The situations were 
easily discriminable. The only consistancy was the saccharin used in both situations. In addition, Nachman, Rauschenberger, and Ashe (1977) found that the lick tube dispensing the fluid could be used to discriminate - even with the same fluids. This is what Nachman et al. (1977) refer to as "tongue-tactile cues". The present study employed different types of fluid dispensers in the Cue Exposure phase, than in the Conditioning and Test II phases. This suggests that the taste of saccharin out of a specific drinking spout in a specific context may have become an aversive stimulus, whereas the taste of saccharin in a different dispenser in a different context was not an aversive stimulus. If this discrimination occurred in the present experiment an aversion to saccharin would be demonstrated in the Test II situation but not in Test I. The results support this conclusion. Drinking saccharin in the Conditioning/Test II context out of a distinctive spout became an aversive event whereas no suppression of bar pressing was evidenced in Test $I$. The absence of a suppression of responding to the tone during Test I indicates that the tone did not become an aversive stimulus. This could be due to (1) external stimuli not being able to become higher order or sensory preconditioned stimuli for internal events, or (2) the taste of saccharin not becoming an aversive first order 
stimulus in the given context. Based on previous research which demonstrate external stimuli serving as higher order or sensory preconditioned stimuli for internal events (Archer \& Sjoden, 1982; Best et al., 1973; Krane, 1980; Morrison \& Collyer, 1974; Rescorla, 1980), it can be suggested that the taste of saccharin did not become an aversive first order stimulus in the Test I context. Context may have played a major role in preventing the establishment of an external stimulus as a higher order conditioned or a sensory preconditioned stimulus for an internal event.

An alternate explanation for the present results is that a Type II error was made. Several things could have influenced such an error. Given the limited range of the raw values of the proportions (approximately $.3-.7$, see Appendix A2), the dependent measure (suppression of bar pressing) may have been an unreliable, insensitive one. The values of actual bar presses are presented in Appendix A3. In addition, the treatment, that is, the cue exposure phase, was subtle. Two pairings a day for five days led to a total of 10 trials (20\% of the total number of trials). This could have led to a small treatment effect. Small sample size $(n=8)$ could also have affected the power of the test. An alternate test that could have been used was a Chi-squared test which is a non-parametric test, 
which in and of itself has lower power than a parametric one.

Although the hypotheses of this study were not directly supported, this research does seem to lend support to a general set of laws for learning. 


\section{APPENDIX AI}

Means and SDs of Response Suppression Ratios During Test I

TRIALS

\begin{tabular}{|c|c|c|c|c|c|c|c|}
\hline CONDITION & ORDBR & & 1 & 2 & 3 & 4 & 5 \\
\hline & PRE & $\mathbf{M}$ & .376 & .599 & .520 & .521 & .604 \\
\hline \multirow[t]{3}{*}{$\mathrm{E}$} & & SD & .319 & .292 & .183 & .162 & .295 \\
\hline & POST & & .331 & .458 & .601 & .605 & .526 \\
\hline & & & .202 & .156 & .239 & .236 & .167 \\
\hline \multirow{4}{*}{$\mathrm{Cl}$} & PRE & & .376 & .501 & .581 & .546 & .645 \\
\hline & & & .203 & .189 & .207 & .142 & .181 \\
\hline & POST & & .482 & .491 & .485 & .526 & .478 \\
\hline & & & .241 & .158 & .130 & .113 & .156 \\
\hline \multirow{4}{*}{ C2 } & PRE & & .286 & .480 & .378 & .573 & .375 \\
\hline & & & .104 & .129 & .104 & .193 & .253 \\
\hline & POST & & .427 & .426 & .441 & .588 & .631 \\
\hline & & & .207 & .248 & .218 & .145 & .177 \\
\hline \multirow{4}{*}{ C3 } & PRE & & .324 & .627 & .571 & .512 & .487 \\
\hline & & & .313 & .279 & .287 & .253 & .338 \\
\hline & POST & & .490 & .442 & .601 & .495 & .538 \\
\hline & & & .225 & .193 & .208 & .267 & .181 \\
\hline
\end{tabular}




\section{APPENDIX A2}

Means and SDs of Saccharin Consumption Ratios During

Test II

QRDER

CONDITION

PRE

POST

$\mathrm{E}$

$\begin{array}{ll}\mathrm{M} & .37 \\ \mathrm{SD} & .16\end{array}$

.24

SD $\quad 16$

.09

$\mathrm{Cl}$

.28

.23

.18

.14

C2

.67

.71

.14

.21

C3

.66

.59

.14

.19 
APPENDIX A3

Mean Number of Responses for Test I During the $30 \mathrm{~s}$ Prior to the Tone (PT) and $30 \mathrm{~s}$ Tone Periods ( $T$ )

\begin{tabular}{lllllll}
\hline & \multicolumn{5}{c}{ TRIAL } & \\
Group & 1 & 2 & 3 & 4 & 5 \\
\hline & $M$ & SD & & & &
\end{tabular}

PRE E

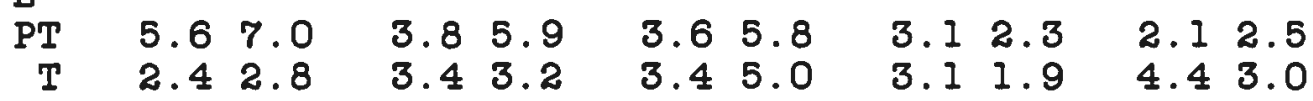

POST E

$\begin{array}{rllllllllll}\text { PT } & 4.8 & 3.0 & 5.8 & 3.8 & 2.8 & 2.2 & 3.4 & 3.0 & 3.9 & 1.9 \\ \text { T } & 1.9 & 1.4 & 5.0 & 3.2 & 3.8 & 2.7 & 3.8 & 2.3 & 4.3 & 1.9\end{array}$

PRE C1

PT $\quad \begin{array}{lllllllll}4.4 & 1.4 & 4.1 & 2.4 & 3.3 & 2.6 & 3.6 & 2.0 & 2.62 .2\end{array}$

T $2.92 .0 \quad 4.6 \quad 3.4 \quad 4.32 .4 \quad 4.42 .2 \quad 3.93 .0$

POST Cl

$\begin{array}{rllllllllll}\text { PT } & 3.8 & 2.3 & 5.0 & 3.9 & 4.1 & 1.9 & 4.5 & 3.2 & 5.6 & 3.0 \\ \text { T } & 2.9 & 1.2 & 4.9 & 3.7 & 4.5 & 3.3 & 5.3 & 3.6 & 5.1 & 3.7\end{array}$

PRE C2

PT $\quad 5.4 \quad 1.9 \quad 5.52 .1 \quad 4.02 .6 \quad 4.62 .2 \quad 3.42 .2$

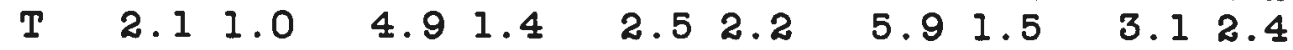

POST C2

PT $\quad \begin{array}{lllllllll}4.8 & 3.8 & 3.1 & 3.5 & 5.4 & 5.1 & 3.0 & 2.1 & 3.42 .7\end{array}$

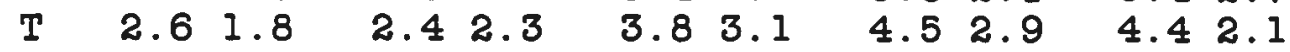

PRE C3

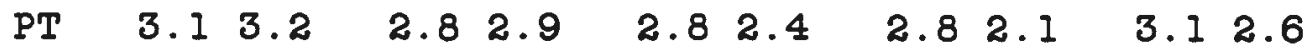

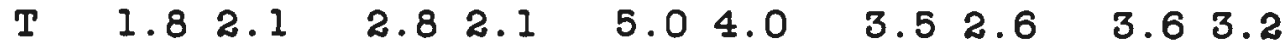

POST C3

PT $4.9 \quad 3.0 \quad 6.3 \quad 4.5 \quad 3.0 \quad 1.5 \quad 4.0 \quad 3.2 \quad 5.03 .4$

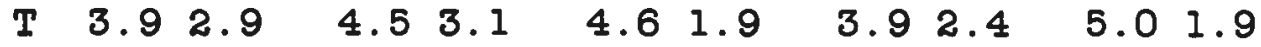


References

Adams, Jack A. (1976). Learning and Memory: An Introduction, The Dorsey Press; Homewood, Illinois. Archer, T., \& Sjoden, P. (1982). Higher-order conditioning and sensory preconditioning of a taste aversion with an exteroceptive CS-sub-1. Quarterly Journal of Experimental Psychology: Comparative and Physiological Psychology, 34B , 1-17.

Archer, T., Sjoden, P. \& Carter N. (1979). Control of taste-aversion extinction by exteroceptive cues. Behavioral and Neural Biology, 25 , 217-226.

Berk, A.M. \& Miller, R.R. (1978). Licl-induced aversions to audiovisual cues as a function of response measure and CS-US interval. Behavioral Biology, 24, 185-208.

Best, P.B., Best, M.R., \& Mickley, A. (1973).

Conditioned aversion to distinct environmental stimuli resulting from gastrointestinal distress. Journal of Comparative and Physiological Psychology, $85,250-257$.

Bitterman, M.E. (1964). Classical conditioning in the goldfish as a function of the CS-US interval. Journal of Comparative and Physiological Psychology , $58,359-366$. 
Bitterman, M.E. (1965). The CS-UCS interval in classical conditioning and avoidance conditioning. In Prokasy (Ed, ) Classical Conditioning, , Appleton-Century-Crofts: New York, 1-19.

Bond, N.W. E DiGiusto, E.L. (1976). One trial higher-order conditioning of a taste aversion. Australian Journal of Psychology, 28, 53-55. Boneau, C.A. (1958). The interstimulus interval and the latency of the conditioned eyelid response. Journal of Experimental Psychology , 56 , 464-471. Boyd, T.L., \& Levis, D.J. (1976). The effects of single-component extinction of a three component serial CS on resistance to extinction of the conditioned avoidance response. Learning and Motivation , $7,517-531$.

Braveman, N., \& Capretta, P.J. (1965). The relative effectiveness of two experimental techniques for the modification of food preferences in rats. Proceedings of the 73rd Annual Convention of the American Psychological Association , 129-130. Brodgen, W.J. (1939). Sensory pre-conditioning. Journal of Experimental Psychology, 25, 323-332. Brodgen, W.J., Lipman, E.A., \& Culler, E. (1938). The role of incentive in conditioning and extinction. American Journal of Psychology, 51, 109-117. Church, R.M. (1969). Response suppression. In 
Campbell \& Church (Eds.) Punishment and Aversive

Behavior, Appleton-Century-Crofts: New York.

Colby, J.J. \& Smith, N.F. (1977). The effect of three procedures for eliminating a conditioned taste aversion in the rat. Learning and Motivation, 8, 404-413.

Corriveau, D., \& Smith, N.F. (1978). Fear reduction and safety testing behavior following response prevention: A multivariate analysis. Journal of Experimental Psychology: General , $107,145-158$. Dietz, M.N., \& Capretta, P.J. (1966). Modification of sugar-saccharin preference in rats as a function of electrical shock to the mouth. Proceedings of the 74th Annual Convention of the American Psychological Association, 161-162.

Dragoin, W.B. (1971). Conditioning and extinction of taste aversions with variations in intensity of the CS and US in two strains of rats. Psychonomic Science, 22, 303-304.

Dragoin, W., Hughes, G., Devine, M. \& Bentley, J. (1973). Long term retention of conditioned taste aversions: Effects of gustatory interference. Psycholosical Reports , $33,511-514$.

Ebel, H.C., \& Prokasy, W.F. (1963). Classical eyelid conditioning as a function of sustained and shifted interstimulus intervals. Journal of Experimental 
Psychology, 65, 52-58.

Estes, W.K., \& Skinner, B.F. (1941). Some quantitative properties of anxiety. Journal of Experimental Psychology, 29, 390-400.

Garcia, J., Bimeldorf, D.J., \& Boelling, R.A. (1955). Conditioned aversion to saccharin resulting from exposure to gamma radiation. Science, 122, 157-158.

Garcia, J., \& Boelling, R.A. (1966). Relation of cue to consequence in avoidance learning. Psychonomic Science, $4,123-124$.

Garcia, J., MoGowan, B.B., Ervin, F.R., \& Koelling, R.A. (1968). Cues: Their effectiveness as a function of the reinforcer. Science, 160, 794-795.

Hawk, G., \& Riccio, D.C., (1977). The effects of a conditioned fear inhibitor (CS-) during response prevention upon the extinction of an avoidance response. Behaviour Research and Therapy, 15, 97-102 .

Heth, C.D., Rescorla, R.A. (1973). Simultaneous and backward fear conditioning in the rat. Journal of Comparative and Physiological Psychology , $82,434-443$.

Infurna, R.N., Stelnert, P.A. , Freda, J.S., \& Spear, N.E. (1979). Sucrose preference and LiCl 1liness-induced aversion as a function of drug dose 
and phase of the illumination cycle. Physiology and Behavior , 22, 955-961.

Kalat, J.W. (1974). Taste salience depends on novelty, not concentration, in taste aversion learning in the rat. Journal of Comparative and Physiological

Psychology, $86,47-50$.

Kamin, L. (1965). Temporal and intensity characteristios of the conditioned stimulus. In Prokasy (Ed.) Classical Conditioning, Appleton-Century-Crofts: New York.

Klein, S., Freda, J. \& Mikukla, P. (1985). The influence of a taste cue on an environmental aversion: Potentiation or overshadowing. The Psychological Record , $35,101-112$.

Klosterhalfen, S. Elosterhalfen, พ. (1985).

Conditioned taste aversion and traditional learning. Psychological Research, $47,71-94$.

Krane, R.V. (1980). Toxiphobia conditioning with exteroceptive cues. Animal Learning and Behavior, $8,513-523$.

Larsen, D., \& Hyde, T.S. (1977). A comparison of learned aversions to gustatory and exteroceptive cues in rats. Animal Learning and Behayior, $\underline{5}$, $17-20$.

Levy, B.J. (1975). Large-sample pair-wise comparisons involving correlations, proportions, or variances. 
Psychological Bulletin, 82, 174-176.

Monti, P.M., of Smith,N. (1976). Residual fear of the CS

as a function of response prevention after avoidance

or classical defensive conditioning in the rat. Journal of Experimental Psychology: General , 105 . 148-162.

Morrison, G.R., \& Collyer, R. (1974). Taste-mediated conditioned aversion to an exteroceptive stimulus following LiCl poisoning. Journal of Comparative and Physiological Psycholosy, 86, 51-55.

Nachman, M., Rauschenberger, J. \& Ashe, J. (1977).

Studies of learned aversions using non-gustatory stimuli. In L. M. Barker, M.R. Best and M. Domjan (Eds.), Learning Mechanisms in Food Selection, Waco, Texas: Baylor University Press.

Neill, S.A. (1980). Persistance of Fear Reduction Resulting from Response Prevention. Unpublished master's thesis, University of Rhode Island, Bingston, RI.

Page, H.A. (1955). The facilitation of experimental extinction by response prevention as a function of the acquisition of a new response. Journal of Comparative and Physiological Psycholosy , 48 , 14-16.

Page, H.A., \& Hall, J.F. (1953). Experimental extinction as a function of the prevention of a 
response. Journal of Comparative and Physiological Psychology, 46, 33-34.

Pavlov, I. (1927). Conditioned Reflexes, London:Oxford University Press.

Prokasy, W.F., Hall, J.F., \& Fawcett, J. (1962).

Adaptation, sensitization, forward and backward conditioning, and pseudoconditioning of the GSR.

Psychological Reports , 10 , 103-106.

Rescorla, R.A. (1980). Simultaneous and successive associations in sensory preconditioning. Journal of Experimental Psychology: Animal Behavior

Processes , 6, 207-216.

Revusky, S., \& Garcia, J. (1970). Learned associations over long delays. The Psychology of Learning and Motivation: Advances in Research and Theory, 4 , $1-84$.

Schiff, R., Smith, N., \& Prochaska, J. (1972).

Extinction of avoidance in rats as a function of duration and number of blocked trials. Journal of Comparative and Physiological Psychology, 81 , 356-359.

Seligman, M.B.P. (1970). On the generality of the laws of learning. Psychological Review, 77, 406-418. Seligman, M.B.P. (1972). Phobias and preparedness. In Seligman \& Hager, Biological Boundaries of Learning , Appleton-Century=Crofts : New York. 
Seligman, M.E.P., \& Hager J.I. (1972). Biological Boundaries of Learning, Appleton-Century-Crofts:New York.

Shipley, R.H., Mock, L.A., \& Levis, D.J. (1971). Effects of several response prevention procedures on activity, avoldance responding and conditioned fear in rats. Journal of Comparative and Physiological Psychology , $77,256-270$.

Smith, J.C., \& Roll, D.L. (1967). Trace conditioning with X-rays as an aversive stimulus. Psychonomic Science , 9, 11-12.

Spring, D. (1972). Fear Reduction in Rats Through Avoidance Blocking . Unpublished master's thesis, University of Rhode Island, Kingston, RI. Sullivan, L.G. (1984). Long delay and selective association in food aversion learning: The role of cue location. Quarterly Journal of Experimental Psychology, 36B , 65-87. 